\title{
Association of CCL7 Promoter Polymorphism with Responsiveness to Allergen in Cynomolgus Macaque Model of Asthma
}

\author{
Sela Septima Mariya ${ }^{1}$, Fitriya Nur Annisa Dewi ${ }^{1,2}$, Eric Hayes ${ }^{3}$, Villiandra ${ }^{2}$, \\ Yasmina Arditi Paramastri ${ }^{1,4}$, Diah Iskandriati ${ }^{1,2}$, Uus Saepuloh ${ }^{1}$, Joko Pamungkas ${ }^{1,5}$, \\ I Nengah Budiarsa ${ }^{1,2}$, Dondin Sajuthi ${ }^{1,5 *}$ \\ ${ }^{1}$ Primate Research Center, Bogor Agricultural University, Jl. Lodaya II No. 5, Bogor 16151, Indonesia \\ ${ }^{2}$ PT. Bimana Indomedical, J1. Lodaya II No. 5, Bogor 16151, Indonesia \\ ${ }^{3}$ Porsolt SAS, Le Genest-Saint-Isle, Glatigné, 53940 Le Genest-Saint-Isle, France \\ ${ }^{4}$ Comparative Medicine, National University of Singapore, 21 Lower Kent Ridge Road, Singapore 119077 \\ ${ }^{5}$ Faculty of Veterinary Medicine, Bogor Agricultural University, J1. Agatis, Bogor 16680, Indonesia \\ *Corresponding author. E-mail: sajuthi@indo.net.id
}

Received date: Dec 12, 2019; Revised date: Apr 29, 2020; Accepted date: May 11, 2020

\section{Abstract}

B ACKGROUND: C-C motif Ligand 7 (CCL7) has been reported to be associated with asthma severity in humans. Cynomolgus macaques (Macaca fascicularis; $M f$ ) are often used as animal model of asthma but little is known about $M f$ genetic profile such as polymorphism. Our aim was to identify $C C L 7$ polymorphism in $M f$ as a potential surrogate marker for identification of allergen responsiveness in the $M f$ model of asthma.

METHODS: Real-time PCR was performed on archive of bronchoalveolar fluid samples previously collected from $M f$ that were exposed to allergen. Expression of CCL7 mRNA was evaluated, and sequencing technique was used to identify polymorphism in this gene.
RESULTS: The results showed that CCL7 expression did not differ between $M f$, despite a trend of lower expression in $M f$ that exhibited high response to allergen. By direct DNA sequencing of $C C L 7,10$ sequence variants were identified; three in promoter region (-460 G/A, $-459 \mathrm{~A} / \mathrm{G},-456$-/A ), two in exon $1(9 \mathrm{~A} / \mathrm{G}, 65 \mathrm{G} / \mathrm{C})$, four in intron $1(135 \mathrm{~T} / \mathrm{C}$, $254 \mathrm{~T} / \mathrm{C}, 420 \mathrm{~T} / \mathrm{C}, 453 \mathrm{~A} / \mathrm{G})$, and one in intron 2 (1205 T/A).

CONCLUSION: There was an association between $M f$ sensitivity to allergen with $C C L 7$ promoter polymorphism at (-456 -/A). These results suggest that $C C L 7$ may be a potential genetic marker to identify $M f$ sensitivity to allergen, which could be a useful tool to efficiently select for $M f$ model of asthma.

KEYWORDS: asthma, CCL7, allergy, Ascaris suum, nonhuman primate

Indones Biomed J. 2020; 12(2): 183-8

\section{Introduction}

Respiratory diseases including asthma are often complex polygenic disorders that manifest as the result of exposure of genetically susceptible individuals to airway reactive substances within their environments.(1) Asthma is a chronic disorder of the respiratory tract, in which a severe inflammation causes obstruction of the airflow, airway hyperresponsiveness to stimuli, bronchospasm and symptoms such as cough, wheezing, dyspnoea and chest tightness.(2) Asthma remains the most common respiratory disease both in developing and developed countries. $(3,4)$ Study in families affected with asthma suggest several chromosome regions may contain potential candidate genes associated with the disease. $(5,6)$

The nonhuman primate (NHP) is genetically, anatomically and immunologically similar to humans and represents a valuable model system for human airway disease.(7-9) Studies have reported the use of $M f$ in research of asthma drugs $(10,11)$, but details on the model's genetic background is limited. Even though $M f$ are spontaneously 
responsive to allergen $(12,13)$, the skin and airway responsiveness may vary between individuals (14), which could be important for study interpretation.

The pathogenesis of asthma has long been studied, and it was demonstrated that CC chemokines play an important role. They are a subfamily of chemokines containing 4 or 6 cysteins. CC chemokines and their receptors contribute in facilitating leukocyte function, and hence, developing immune response15. Protein C-C motif Ligand 7 (CCL7), previously known as Monocyte Chemotactic Protein-3 (MCP-3), is a secreted during inflammatory process of asthma. CCL7 is a member of C-C chemokine family located on chromosome 17q11.2-q12.(15) CCL7 polymorphisms in several sites in the human genome have been associated with asthma severity in certain populations. $(16,17)$ Importantly, CCL7 expression was found high in asthmatic monkeys. $(18,19)$ However, it is unknown if the nucleotide sequence profile of this gene is a determinant for allergen hypersentivity in monkeys.

In this study, we identified mRNA expression and sequenced six regions of $C C L 7$ gene in 8 adult $M f s$. These animals were reported to exhibit different responses to Ascaris suum, a classic allergen used in asthma studies. The primary objective was to identify single nucleotide polymorphism (SNP) within the CCL7 gene in $M f$ as a potential genetic marker to identify allergen responsiveness.

\section{Methods}

\section{Samples}

This research used archived bronchoalveolar lavage (BAL) fluid samples collected from $M f$ that were enrolled in an asthma study.(14) Briefly, the asthma study was performed in Primate Research Center at Bogor Agricultural University and PT. Bimana Indomedical following approval from the Institutional Animal Care and Use Committee (IACUC) with ethical approval No. PTBI IACUC 05-07-1R. The results have been reported wherein $M f$ showed differential skin and airway responses to A. suum, and were defined as high and low responders. High and low responders were
Mf that showed asthma response following exposure to low and high dose of $A$. suum, respectively.(14) Here, we used 8 archive samples from both groups $(n=4$ from high responders and $n=4$ from low responders).

\section{Gene Expression Of CCL7, CCR1, and CCR3}

The isolation of mRNA from BALf samples was performed using the Qiagen RNAeasy mini kit (Qiagen, Hilden, Germany). The isolated mRNA concentration was measured using NanoDrop (Thermo Fisher, Waltham, Massachusetts, USA). A total of $0.7 \mathrm{ng} / \mu \mathrm{L}$ mRNA was used as a template for reverse transcription process. The cDNA synthesis was performed with Superscript III RT enzyme from Invitrogen (Life Technology, Eugene, Oregon, USA) according to the company instructions. The molecular expression level of CCL7, CCRI, and CCR3 was evaluated using Realtime PCR technique (qRT-PCR). qRT-PCR was done using SsoFast ${ }^{\mathrm{TM}}$ EvaGreen ${ }^{\circledR}$ Supermix (Biorad, Hercules, California, USA) according to the company manual. The primer used is presented in Table 1. The qRT-PCR data were evaluated using delta $\mathrm{Ct}$ method using glyceraldehyde 3-phosphate dehydrogenase (GAPDH) as the reference gene, and statistical analysis was performed using SPSS 18 (IBM Corporation, Armonk, New York, USA).

\section{Polymerase Chain Reaction (PCR) and Sequencing}

The same subset of BALf samples used for gene expression analysis was also used for sequencing purposes. DNA isolation from BALf was performed using DNeasy Blood and Tissue Kit Qiagen (Qiagen). Ampilification of $5 \mu \mathrm{L}$ DNA was performed by Hotstart PCR technique using KAPA Hotstart Master Mix PCR (KAPA Biosystem, Wilmington, North Carolina, USA). The primers for CCL7 used in this study were amplified from promoter to terminator region (Figure 1) referred to prior publication 17 with modification (Table 2). The PCR technique was performed in Thermo cycler Applied Biosystem Perkin Elmer 9700 with program incubation $94^{\circ} \mathrm{C}$ for 5 minutes, $94^{\circ} \mathrm{C}$ denaturation for 30 seconds, $60^{\circ} \mathrm{C}$ annealing for 30 seconds, extension of DNA at $72^{\circ} \mathrm{C}$ for 30 seconds, and post PCR $72^{\circ} \mathrm{C}$ for 5 minutes. The denaturation stage until the extension of the DNA strands

Table 1. Primer sequences used for RealTime PCR.

\begin{tabular}{llll}
\hline \multicolumn{1}{c}{ Gene } & \multicolumn{1}{c}{ Forward $\left(\mathbf{5}^{\prime} \mathbf{-} \mathbf{3}\right.$ ') } & \multicolumn{1}{c}{ Reverse (5'-3') } & \multicolumn{1}{c}{ Species } \\
\hline$C C L 7$ & GAGCTACAGAAGGACCACCAGT & AAGTCCTGGACCCACTTCTG & Human ${ }^{17}$ \\
$C C R 1$ & CTGGTTGGAAACATCCTGGT & GGAAGCGTGAACAGGAAGAG & Human ${ }^{29}$ \\
$C C R 3$ & GTGTTCACTGTGGGCCTCTT & GTGACGAGGAAGAGCAGGTC & Human $^{28}$ \\
GAPDH & CGGATTTGGTCGTATTGG & TCAAAGGTGGAGGAGTGG & Human $^{34}$ \\
\hline
\end{tabular}




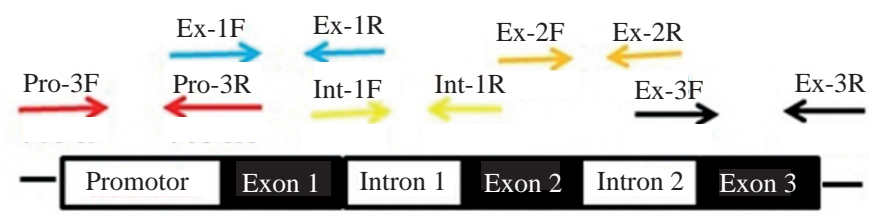

Figure 1. Primer position in analysis of $\boldsymbol{C} \boldsymbol{C L}$ T SNPS in $\boldsymbol{M} \boldsymbol{f}$. $\boldsymbol{M} f$ covered the region of promoter (Pro-3F and Pro-3R), exon 1 (Ex-1F and Ex-1 R), exon 2 (Ex-2F and Ex-2 R), exon 3 (Ex-3 F and Ex-3 R), and intron 1 (Int-1F and Int-1 R). Primers are indicated as arrows and the target region are indicated as block.

was repeated 40 cycles. The PCR results were visualized by agarose gel electrophoresis $1.8 \%$ and read using GelDoc 2000 (Biorad, Hercules, California, USA). DNA sequencing was performed at 1 st BASE ( $1{ }^{\text {st }}$ BASE, Selangor, Malaysia). DNA sequencing results were analyzed using BioEdit program (Ibis Biosciences, Carlsbad, California, USA).(20) Analysis of sequencing results was carried out using Clustal W program of MEGA 5.2 (Pennsylvania State University, Pennsylvania, USA).(21) Analysis of haplotype was carried out using DnaSP program (Universitat de Barcelona, Barcelona, Spain).(22)

\section{Results}

The coding sequences of $M f C C L 7$ was submitted to NCBI Genbank (MF062250).(23) The qRT-PCR results showed a trend of difference in the mRNA expression of CCL7 and its receptors between low and high responders. Figure 2 shown gene expression of $C C L 7, C C R 1$, and $C C R 3$ of high responder group were down regulated compared to low responder with fold change value as $0.217,0.228$, and 0.115 , respectively. Although not statitically significant, there was a trend of higher CCL7 expression in low responders compared to high responders $(p=0.081)$. Similar expression pattern was found on $C C L 7$ 's receptors with $p$-values of 0.063 for $C C R 1$ and 0.073 for $C C R 3$.

DNA samples were evaluated to identify $C C L 7$ polymorphism. Our analysis indicated 4 areas in the $C C L 7$ gene that showed nucleotide sequence variation (Figure 3); the promoter (-460 G/A, -459 A/G, -456 -/A ), exon 1 (9 A/G, $65 \mathrm{G} / \mathrm{C})$, intron 1 (135 T/C, $254 \mathrm{~T} / \mathrm{C}, 420 \mathrm{~T} / \mathrm{C}$, $453 \mathrm{~A} / \mathrm{G})$, and intron 2 (1205 T/A). Among those, the genetic variation in the promoter region was associated with reactivity phenotype wherein 3 polymorphic sites were found, which produced 4 haplotypes. One haplotype, particularly at position -456 , was evident in animals that had low reactivity to allergen. The number of haplotypes and individual groupings based on these haplotypes are presented in Table 3.

\section{Discussion}

Our study showed an association between polymorphism of $C C L 7$ promoter and $M f$ reactivity to asthma-inducing allergen, whereby a haplotype of $-456 \mathrm{~A} /-$ was exclusive to low responders. Expression of CCL7 mRNA and its

Table 2. Primer sequence for SNP analysis $C C L 7$ in $M f$.

\begin{tabular}{lcccl}
\hline Primer & Region & Amplicon & $\begin{array}{c}\text { Annealing } \\
\text { Temperature }\end{array}$ & Primer Sequence \\
\hline MCP-3 pro-3 & Promoter & 613 & 55 & F: TGGGTTTTAGAAAGCCACCAGG \\
& & & & R: GGGCAATGTGCTTCAAGGAGAA \\
\hline MCP-3 ex-1 & Exon 1 & 640 & 57 & F: AAGTGCACCGGCTCAGCAGATT \\
& & & & R: TGCAGAGCTGCTGTTTCTGGAA \\
\hline MCP-3 ex-2 & Exon 2 & 584 & 57 & F: CAAAGACACCGGACTTGGGACG \\
\hline MCP-3 ex-3 & Exon 3 & 534 & 58 & F: AGACTTCAGTTCTTTTATCCTGG \\
& & & & R: TCCACCAAAATCCATGGAAGA \\
\hline MCP-3 int-1 & Intron 1 & 629 & 55 & F: AGCAGAGTTTGGGATCGGGTGA \\
& & & & R: ACACATTACAGCTTCCGGGGA \\
\hline MCP-3 int-2 & Intron 1-terminater & 1235 & 56 & F: TTTGGGATCGGGTGATCAAAAA \\
& & & R: AATCACTCTGAGAAAGGACAGGGT \\
\hline
\end{tabular}




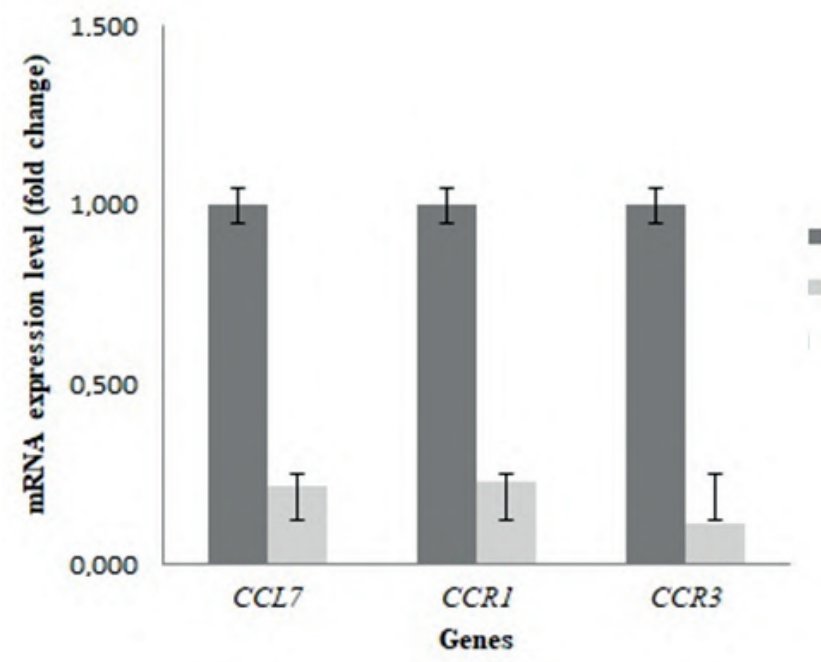

receptors appeared to be higher in low responders group although they were not found to be statistically significant.

Asthma studies involving $M f$ rarely take into consideration the genetic background of the model despite the fact that asthma is a polygenic disorder and that genetic polymorphism are commonly found in nonhuman primates more than in humans. $(24,25)$ We have recently characterized CCL7 mRNA of Indonesian Mf.(23) To our knowledge, our study is the first to indicate that CCL7 polymorphism may determine $M f$ responsiveness to allergen and asthma. The grouping based on CCL7 promoter haplotype showed an interesting result as Haplotype I was found to be specific to monkeys in the low responder group. Research on association of SNPs in the gene encoding chemokine and asthma phenotype is a developing field. A study in the Korean population found CCL7 polymorphism in the promoter region although it was not associated with asthma severity.(17) In contrast, polymorphism within the CCL7 promoter region was associated with atopic asthma in Indian population.(16) The association between asthma response and genetic variation also occurs in other chemokine- related genes. Previous study reported a link between CCL2 polymorphism and the nature of asthma response in families with asthma in Tunisia.(26)

$C C L 7$ is one of the chemokines that plays a role in the pathophysiology of asthma. It has been reported that higher CCL7 expression was associated with an increase in the number of eosinophils in bronchial mucosa of individuals with asthma compared to healthy individuals.(17) In a microarray study of asthmatic monkeys, CCL7 was the gene with the highest expression.(18) Here, we performed a preliminary study with limited number of animals and found a trend of differential CCL7 expression between asthmatic monkeys of different reactivity to allergen. Although not statistically significant, the expression of CCL7 and its receptors showed a higher trend in the BALf of low responders compared to high responders. As the BALf samples were taken at 24 hours following the asthma episode induced by airway challenge, this result may indicate that the chemokine response could have occurred immediately in the high responders which caused the expression to have decreased by 24 hours. In contrast,

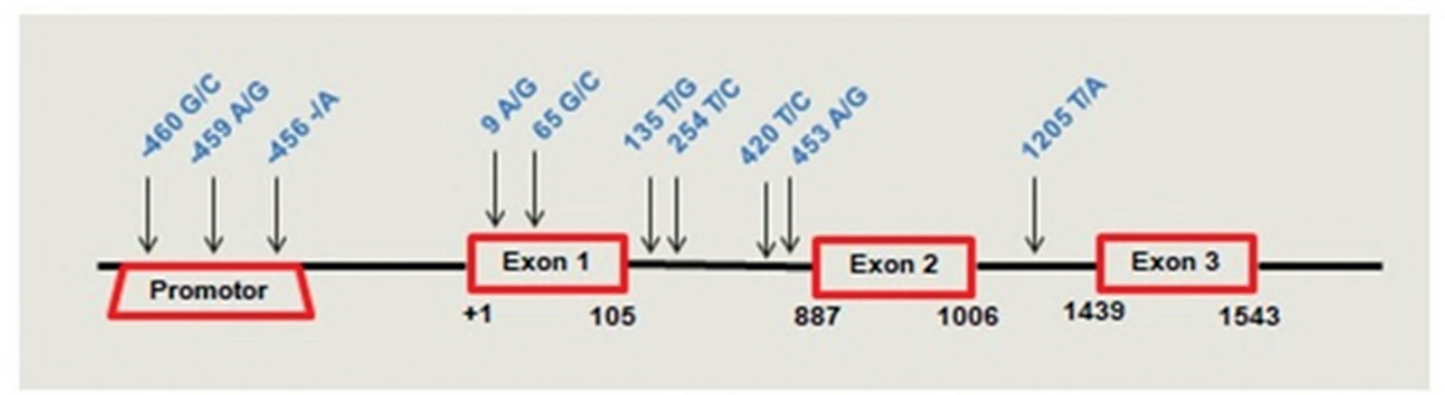

Figure 3. Gene map and SNPs position in $C C L 7 M f$. Coding exons are marked by red blocks and first base of translation site was denoted as nucleotide +1 . Nucleotide position of the genes was indicated with the number and the arrow was indicated position of SNPs. There are SNPs in Promoter (-460 G/A, -459 A/G, -456 -/A ), Exon 1 (9 A/G, 65 G/C), Intron 1 (135 T/C, 254 T/C, 420 T/C, 453 A/G), and Intron 2 (1205 T/A). 
Table 3. Identified SNP in promoter regions and haplotypes.

\begin{tabular}{lccccc}
\hline \multirow{2}{*}{ Haplotype } & \multicolumn{3}{c}{ Promoter Region } & & Phenotype Remarks \\
\cline { 2 - 4 } & $\mathbf{- 4 6 0}$ & $\mathbf{- 4 5 9}$ & $\mathbf{- 4 5 6}$ & & \\
\hline I & A & G & A & 4 & Low responders \\
II & A & G & - & 1 & High responder \\
III & A & A & - & 1 & High responder \\
IV & G & A & - & 2 & High responders \\
\hline Total samples & & & & $\mathbf{8}$ & \\
\hline
\end{tabular}

low reactivity responders may have exhibited a slower chemokine response. It has been previously reported that the expression of CCL7 and other chemokines increased within 4 hours and decreased by $8 \mathrm{~h}$ post $A$. suum inhalation and was back to near base line by 24 hours.(18) Since there was no BALf sample that represented an earlier timepoint (i.e., less than 24 hours post-allergen challenge), it is unclear whether low and high reactivity responders react differently during the acute phase of allergen inhalation. Alternatively, the result may be indicative of a compensatory mechanism that occurs with the high reactivity responders in their effort to decrease airway hyper-responsiveness. In nonallergic mice, down regulation of CCL7 was found to reduce rhinovirus-induced airway hyper-reactivity.(27) Compensation is a relatively common mechanism during asthma response whereby in transgenic models of asthma, it has been reported that compensatory mechanisms such as those involving up regulation of G-protein or ion channels occur to attenuate airway responsiveness or smooth muscle contractility. $(28,29)$

The $C C L 7$ protein is a ligand which binds to receptors such as CCR1, CCR2 and CCR3. The binding activates monocytes, lymphocytes, dendritic cells, NK cells, and granulocytes.(30) In line with CCL7 expression, we found that $C C R 1$ and $C C R 3$ gene expressions of the high responders also showed a trend of lower expression compared to low responders. $C C R 2$ and its other ligand (i.e., CCL2), however, showed a significantly higher expression in low responders. (31) This finding may indicate a synergistic role between $C C L 7$ and its receptors in the pathogenesis of asthma. The RNA expression analysis from $M f$ BALf in this study are also limited to the airway response after 24 hours antigen challenge, which may not be relevant to the asthmatic lung or reflect the chronic aspect of asthma.

This study also suggests the likelihood that polymorphisms in the $C C L 7$ gene promoter region are affect for gene expression of $C C L 7$. Genetic variation in the promoter region allows for difference in transcription factors and such difference affect gene expression in respiratory tract muscles.(32) Our findings require further investigation to validate the use of $C C L 7$ as a genetic marker to determine $M f$ reactivity to asthma-inducing allergens as a refined way to select for animals in a more efficient manner.

Information of $C C L 7$ promoter haplotype may be a useful tool to identify $M f$ of certain asthma profile. Prescreening of animals using such information will allow for an efficient and more accurate selection of asthma model candidate, and eventually lead to less variation in animal response during the study. As of now, skin test using allergens remains as the tool for selection of hypersensitive $M f$. This process involves injection of allergen in several sites on the skin performed under anaesthesia. The use of genetic marker to select $M f$ candidate for asthma study needs to be developed further as a refined approach to improve animal welfare. This follows the principles of 3Rs (reduction, refinement and replacement), which is an important aspect in every research that involves animals. $(33,34)$

\section{Conclusion}

Polymorphism in $C C L 7$ promoter region was associated with hyper-responsiveness of $M f$ to $A$. suum, and is therefore a potential genetic marker to support an efficient selection of $M f$ candidates for asthma study.

\section{Acknowledgements}

The study was financially supported by the the Ministry of Research, Technology and Higher Education of the Republic of Indonesia through the grant schemes of Master's Program Leading to Doctoral Degree for Excellent Graduates (PMDSU) grant no. 180/SP2H/LT/DRPM/ III/2016, and the National Grant for University Research (PUPT), grant no. 083/SP2H/PL/Dit.Litabmas/II/2015. We also thank Dr Huda S Darusman for providing edits and inputs to the final manuscript. 


\section{References}

1. Coffman RL, Hessel EM. Nonhuman primate models of asthma. J Exp Med. 2005; 201: 1875-9.

2. Lambrecht BN, Hammad H. The immunology of asthma. Nat Immunol. 2014; 16: 45-56.

3. World Health Organization. Global Asthma Network The Global Asthma Report. Geneva: WHO; 2018.

4. Forum of International Respiratory Societies. The Global Impact of Respiratory Disease - Second Edition. Sheffield: European Respiratory Society; 2017.

5. Barnes PJ, Chung KF, Page CP. Inflammatory mediators of asthma: an update. Pharmacol Rev. 1998; 50: 515-96.

6. Borish L. Genetics of allergy and asthma. Ann Allergy Asthma Immunol. 1999; 82: 413-24.

7. Plopper CG, Hyde DM. The non-human primate as a model for studying COPD and asthma. Pulm Pharmacol Ther. 2008; 21: 755-66.

8. Dybas JM, Andresen CJ, Schelegle ES, McCue RW, Callender NN, Jackson AC. Deep-breath frequency in bronchoconstricted monkeys (Macaca fascicularis). J Appl Physiol. 2006; 100: 786-91.

9. Hyde DM, Miller LA, Schelegle ES, Fanucchi MV, Van Winkle LS, Tyler NK, et al. Asthma: A comparison of animal models using stereological methods. Eur Respir Rev. 2006; 15: 122-35.

10. Mellado M, Martín de Ana A, Gómez L, Martínez C, RodríguezFrade JM. Chemokine receptor 2 blockade prevents asthma in a cynomolgus monkey model. J Pharmacol Exp Ther. 2008; 324: 769-75.

11. Cheng DT, Ma C, Niewoehner J, Dahl M, Tsai A, Zhang J, et al. Thymic stromal lymphopoietin receptor blockade reduces allergic inflammation in a cynomolgus monkey model of asthma. J Allergy Clin Immunol. 2013; 132: 455-62.

12. Bree AG, Schlerman FJ, Wadanoli MD, Wang IM, Goldman SJ, Sypek JP. Development of a model of Ascaris Suum antigen-induced pulmonary inflammation in nonhuman primates. J Inflamm. 2013; 10 (Suppl 1): 2140.

13. Camateros P, Kanagaratham C, Najdekr L, Holub D, Vrbkova J, Coté L, et al. Toll-like receptor 7/8 Ligand, S28463, suppresses ascaris suum-induced allergic asthma in nonhuman primates. Am J Respir Cell Mol Biol. 2018; 58: 55-65.

14. Viliandra, Dewi FN, Paramastri Y, Hayes E, Iskandriati D. Sensitivity to Ascaris suum (AS) extract in Indonesian Macaca fascicularis : skin test reactivity and airway challenge. In: P BP, Setijanto H, Agungpriyono S, Purwantara B, Pamungkas J, Djuwita I, et al., editors. Joint Meeting Of The 3rd International Meeting On Asian Zoo/Wildlife Medicine And Conservation (AZWMC 2008) \& 10th National Veterinary Scientific Conference Of Indonesian Veterinary Medical Association (KIVNAS X PDHI 2008). Bogor: IPB Press; 2008. p.143-4.

15. Hughes CE, Nibbs RJE. A guide to chemokines and their receptors. FEBS J. 2018; 285: 2944-71.

16. Batra J, Das S, Chatterjee R, Chandra S, Ghosh B. Monocyte chemotactic protein (MCP3) promoter polymorphism is associated with atopic asthma in the Indian population. J Allergy Clin Immunol. 2011; 128: 239-42.

17. Park BL, Kim LH, Choi YH, Cheong HS, Park HS, Hong SJ, et al. Association analysis of monocyte chemotactic protein-3 (MCP3) polymorphisms with asthmatic phenotypes. J Biochem Mol Biol. 2005; 38: 77-81.
18. Zou J, Young S, Zhu F, Gheyas F, Skeans S, Wan Y, et al. Microarray profile of differentially expressed genes in a monkey model of allergic asthma. Genome Biol. 2002; 3: research0020. doi: 10.1186/ gb-2002-3-5-research0020.

19. Scott MR Van, Reece SP, Olmstead S, Wardle R, Rosenbaum MD. Effects of acute psychosocial stress in a nonhuman primate model of allergic asthma. 2013; 52: 157-64.

20. Hall TA. BioEdit: a user-friendly biological sequence alignment editor and analysis program for Windows 95/98/NT. Nucleic Acids Symp Ser. 1999; 41: 95-8.

21. Tamura K, Peterson D, Peterson N, Stecher G, Nei M, Kumar S. MEGA5: Molecular evolutionary genetics analysis using maximum likelihood, evolutionary distance, and maximum parsimony methods. Mol Biol Evol. 2011; 28: 2731-9.

22. Librado P, Rozas J. DnaSP v5: A software for comprehensive analysis of DNA polymorphism data. Bioinformatics. 2009; 25: 1451-2.

23. Mariya SS, Dewi FN, Paramastri YA, Iskandriati D, Saepuloh U, Hayes $\mathrm{E}$, et al. Isolation and characterization of C-C chemokine ligand 7 (CCL7) in cynomolgus macaques. HAYATI J Biosci. 2019; 26: 12932.

24. Fawcett GL, Raveendran M, Deiros DR, Chen D, Yu F, Harris RA, et al. Characterization of single-nucleotide variation in Indian-origin rhesus macaques (Macaca mulatta). BMC Genomics. 2011; 12: 311. doi: 10.1186/1471-2164-12-311.

25. Rogers J, Ruano G, Kidd KK. Variability in Nuclear-DNA among Nonhuman-Primates-Application of Molecular Genetic Techniques to Intra-Species and Interspecies Genetic Analyses. Am J Primatol. 1992; 27: 93-105.

26. Chelbi H, Ghadiri A, Lacheb J, Ghandil P, Hamzaoui K, Hamzaoui A, et al. A polymorphism in the CCL2 chemokine gene is associated with asthma risk: a case-control and a family study in Tunisia. Genes Immun. 2008; 9: 575-81.

27. Girkin J, Hatchwell L, Foster P, Johnston SL, Bartlett N, Collison A, et al. CCL7 and IRF7 mediate hallmark inflammatory and interferon responses following rhinovirus 1B infection. J Immunol. 2015; 194 : 4924-30.

28. Valverde MA, Cantero-recasens G, Garcia-elias A, Jung C, Carrerassureda A. Ion Channels in Asthma. J Biol Chem. 2011; 286: $32877-$ 82.

29. Mcgraw DW, Elwing JM, Fogel KM, Wang WCH, Glinka CB, Mihlbachler KA, et al. Crosstalk between G i and G q / G s pathways in airway smooth muscle regulates bronchial contractility and relaxation. J Clin Invest. 2007; 117: 1391-8.

30. Cho YB, Lee WY, Choi SJ, Kim J, Hong HK, Kim SH, et al. CC chemokine ligand 7 expression in liver metastasis of colorectal cancer. Oncol Rep. 2012; 28: 689-94.

31. Mariya SS, Dewi FN, Villiandra, Pramastri YA, Iskandriati D, Hayes E, et al. Ekspresi gen CCL2 dan CCR2 pada cairan bronchoalveolar monyet ekor panjang hewan model penyakit asma. Respirologi Indones. 2018; 38: 127-34.

32. Solway J, Forsythe SM, Halayko AJ, Vieira JE, Hershenson MB, Camoretti-Mercado B. Transcriptional regulation of smooth muscle contractile apparatus expression. Am J Respir Crit Care Med. 1998; 158: S100-8.

33. Prescott MJ, Langermans JA, Ragan I. Applying the 3Rs to non-human primate research: Barriers and solutions. Drug Discov Today Dis Model. 2017; 23: 51-6.

34. Kendall L V, Owiny JR, Dohm ED, Knapek KJ, Lee ES, Kopanke JH, et al. Replacement, refinement, and reduction in animal studies with biohazardous agents. ILAR J. 2018; 59: 177-194. 